\title{
High Flow Bypass for Cavernous Carotid Aneurysms
}

\author{
Maruf Matmusaevi, Temur Duschanov², Yasuhiro Yamada ${ }^{3}$, \\ Katsumi Takizawa ${ }^{4}$, Tsukasa Kawase ${ }^{3}$, Riki Tanaka ${ }^{3}$, Miyatani \\ Kyosuke $^{3}$, Yoko Kato ${ }^{3}$, Ahmed Ansari ${ }^{3}$
}

${ }^{1}$ Republican Specialized Scientific and Practical Medical Center of Neurosurgery, Tashkent, UZBEKISTAN

${ }^{2}$ Department of Neurosurgery, Republican Research Center of Emergency Medicine, Tashkent, UZBEKISTAN

${ }^{3}$ Department of Neurosurgery, Banbuntane Hotokukai Hospital, Fujita Health University, Nagoya, JAPAN

${ }^{4}$ Department of Neurosurgery, Asahikawa Red Cross Hospital, Hokkaido, JAPAN

\begin{abstract}
Introduction and objective: High flow extracranial to intracranial (HF EC-IC) cerebral revascularisation may be necessary in the management of complex skull base tumours and intracranial aneurysms. Bypass grafting can be considered high flow when a radial artery or the saphenous vein is interposed between the extracranial carotids arteries and intracranial vessels. The decision as to whether to use a low flow or high flow bypass is determined by the anticipated cerebral blood flow needed and the availability of a supply source. In this study, we have used this method to bypass for two cases of giant aneurysms of the cavernous sinus part of the ICA. Methods: Two cases of giant ICE aneurysm not amenable to clipping or coiling were taken since 2016. Patients were treated in Neurosurgery department of Fujita Health University Banbuntane Hotokukai Hospital, Nagoya, Japan. During bypass surgery, intraoperative methods were used to determine the patency of the graft artery: Doppler sonography and indocyanine green (ICG) Dual-Image Videoangiography (DIVA). Results: Two patients with symptomatic large and giant cavernous carotid aneurysms were evaluated as not amenable for clipping or endovascular treatment due to location and size of the aneurysm and associated high morbidity risk with these treatment options. In both cases radial artery graft was used for high-flow EC-MCA bypass and proximal internal carotid artery was ligated. Additionally, for high-flow bypass was performed superficial temporal artery (STA) to middle cerebral artery (MCA) bypass. DIVA, ICG and Doppler sonography were used multiple times to assess the patency of graft artery. In one case there was not complete ligation of the IC after postop DSA, the next day was
\end{abstract}


performed reintervention to completely ligate IC. Postoperative course was uneventful, there were no mortality or morbidity. Follow-up showed good recovery and postoperative CT and DSA showed complete occlusion of ligated IC and patent functioning arterial graft. Conclusions: Cavernous carotid aneurysms (CCA) are rare and pose considerable challenges in management. A bypass procedure before parent artery occlusion, preferable to reduce the risks of postocclusion stroke. Intraoperative Doppler sonography and DIVA makes it easy to check the patency of the graft. DIVA is superior over Doppler or ICG in terms of better visualization of related anatomical structures.

Key words: high flow bypass, cavernous carotid aneurysm, radial artery graft

\section{Introduction}

Cavernous carotid aneurysms (CCA) are rare and pose considerable challenges in management. High flow extracranial to intracranial (HF EC-IC) cerebral revascularisation may be necessary in the management of complex skull base tumors and intracranial aneurysms [1]. Bypass grafting can be considered high flow when a radial artery or the saphenous vein is interposed between the extracranial carotids arteries and intracranial vessels. The decision as to whether to use a low flow or high flow bypass is determined by the anticipated cerebral blood flow needed and the availability of a supply source.The risks and benefits of treatment of CCA should be carefully considered because CCAs are not a common pathology, and there are no definite guidelines for treatment currently. Furthermore, data about the natural history and pathogenesis of CCA is limited. Indications for treatment of CCA are summarized in Table 1.[2,3]
Table 1 - Indication of surgical intervention for cavernous part of ICA giant aneurysms

\begin{tabular}{|l|ll|}
\hline \multicolumn{1}{|c|}{$\begin{array}{l}\text { Asymptomatic } \\
\text { aneurysms }\end{array}$} & \multicolumn{1}{c|}{$\begin{array}{c}\text { Symptomatic } \\
\text { aneurysms }\end{array}$} \\
\hline - $\begin{array}{l}\text { Extension of } \\
\text { aneurysm into } \\
\text { subarachnoid space }\end{array}$ & $\bullet \begin{array}{l}\text { Subarachnoid } \\
\text { hemorrhage } \\
\text { - Unbearable ipsilateral } \\
\text { face or retro-orbital } \\
\text { anterior genu of } \\
\text { cavernous carotid } \\
\text { Radiographic } \\
\text { enlargement of } \\
\text { aneurysm }\end{array}$ & $\bullet \begin{array}{l}\text { Progressive } \\
\text { ophthalmoplegia } \\
\text { Sudden, severe } \\
\text { ophthalmoplegia }\end{array}$ \\
\hline
\end{tabular}

Objective of this study is to evaluate effectiveness and surgical techniques of HF EF - IC bypass as appropriate choice of surgical treatment for giant aneurysms of cavernous sinus part of internal carotid artery.

\section{Materials and methods}

This study was conducted on two cases with giant aneurysms of the cavernous sinus part of the ICA that treated with high flow bypass techniques using radial artery (RA)in our practice at Neurosurgery department of Fujita Health University Banbuntane 
Hotokukai Hospital, Nagoya, Japan since 2016. Preoperative evaluation was done with digital subtraction angiography(DSA) and 3D-CT angio. Balloon occlusion test was not perform on these patients, because of atherosclerotic vessels.It is essential to evaluate collateral supply of both intracranial vessels and arteries of non-dominant upper limb using non-invasive fusion or DSA. During surgical procedure that has been done by us, Doppler Sonography (DS), Indocyenine green (ICG) and Dual-Image videoangiography (DIVA) were used to determine the patency of the graft artery.

\section{Case report}

77-year-old female was admitted to our hospital with complains of 3 months history of headache and dizziness. Pre operative 3DCT, MRI and DSA showed a giant aneurysm on the right cavernouspart of internal carotid artery (ICA) that is why diagnosis was a giant right aneurysm of the cavernous portion.

\section{Illustration of procedure}
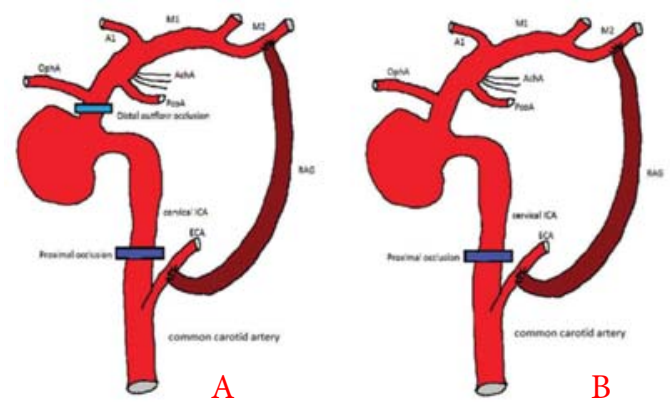

(A) Trapping (cervical internal carotid artery ligation withclipping of $\mathrm{C} 3$ segment of internal carotid artery, just proximal toophthalmic artery origin) of cavernous carotid aneurysm with high-flowbypass. (B) Cervical internal carotid artery ligation with high-flowbypass. Both techniques result in the complete aneurysm thrombosis.First segment of anterior cerebral artery (A1), anterior choroidalartery, first segment of middle cerebral artery (M1), second segmentof middle cerebral artery (M2), ophthalmic artery (OphA), posteriorcommunicating artery $(\mathrm{PcoA})$, and radial artery graft (RAG) [4,5].

\section{Surgical procedure}

First, anastomose the STA to M4 (peripheral part of the M2 to which RA is anastomosed).In the supine position with raisedand turnedhead to the opposite side. Due to presence of many procedures, two operation teams carry out operation by using two microscopes to shorten operation time at the same time. Team for radial graft preparation identifies and confirms collateral circulation using DSA. If there is good collateral circulation RA graft can be obtained at least $18 \mathrm{~cm}$ in length but it is effective to get longer as much as possible because the diverging from the brachiocephalic trunk is the limit of removal on the proximal side, so the distal side is removed as long as possible. During or some time before obtaining RA graft, to let STA-MCA bypass precede for the assist bypass both parietal branch and frontal branch of STA is dissected. It is important to note that the main disadvantage of RA graft is the potential for vasospasm following harvest, which may lead to total occlusion of the vessel and therefore vasospasm is prevented by using pressure distention technique. 
Normal parieto-temporal craniotomy is enough, but removing the bones of middle cranialfossa should be appropriate for the RA graft. As for the common artery, it is not necessary to expose a long segment, yet the external carotidartery that becomes the anastomosis of RA is to be exposed to as high position as possible to choose the anastomotic part. To occlude the central of the ICA, two 1.0 silk threads are put throughthe internal carotid beforehand and identify the posterior belly of the digastric muscle and hypoglossal nerve.Choose the submandibular root as the graft root. As for this root, the length of this graft becomes theshortest, and thus the influence such as the pressure of graft can be avoided. However, pay much attention whether there is not possibilities for torsion or kinking of the graft in the blind part to be occurred.

Making tunnel for graft by using Merkmal consists of following stages; insertion of forefinger from the interval of posterior belly and thehypoglossal nerve from the cervical side till styloid process and then towards the upper front. When it reaches cranial side by Kelly forceps that is inserted in front part of the zygomatic bone from the interval of the temporal muscle and the temporale bone it reaches to cranial side fromthe neck.

On the cranial side, RA graft is anastomosed to the silk thread in the Chest tube.By pulling out the silk thread to the neck side, the RA graft can be indwelled from the head to the neck, after the final confirmation following the anastomosis of the RA graft to
M2 by the 9.0 Nylon suture because of the big vascular size and solid wall of RA, remove the chest tube.First, anastomose the STA to M4 (peripheral part of the M2 to which RA is anastomosed). As for STA performend-toside anastomosis by 10.0 Nylon suture. The purpose of this bypass is to prevent the ischemia complications at thetime of RA-M2 anastomosis that calls for the longer-time temporary blockade (assist bypass) and to monitor the brainsurface MCA pressure to evaluate the patency of RA graft that was completed finally in real time during the operation and in this stage anastomosis process is finished. After that temporary clip in RA in the region close to the anastomosis is done so as to prevent retrograde flows of blood into the graft.Finally,due to the wide vascular diameter proximal part of RA-ECA end-to-side anastomosis can be performed by continuous suture of 7.0 prolene. Before blood flow is restored to the brain, the distal end of the CCA and the proximal side of the ICA are clamped, then the proximal side of the ECA and the distal clamp of the conduit are opened, which allows air to vent through the superior thyroid artery. DS, ICG and DIVA are used during operation after proximal native ICA clamping to demonstrate graft patency and to evaluate the anastomotic sites. After all proximal ICA is ligated and anticoagulation reversed with protamine. In the case of giant aneurysm at the cavernous portion, the parent vessel is not ligated distally, as all of the aneurysm is still thrombosed. 


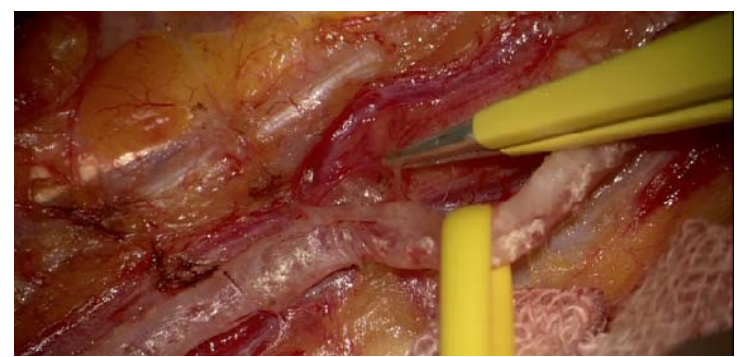

Dissecting the RA while applying appropriate tension with vascular tape

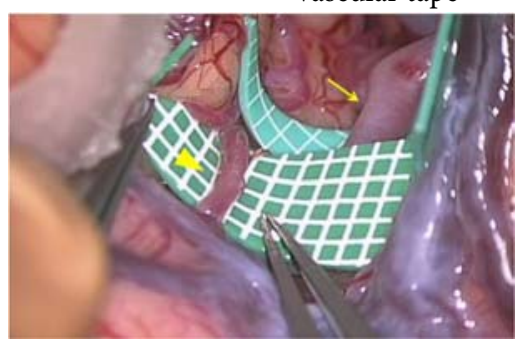

Prepped recipient artery. Arrow: M2 for the RA graft, Arrow head: M4 for the STA

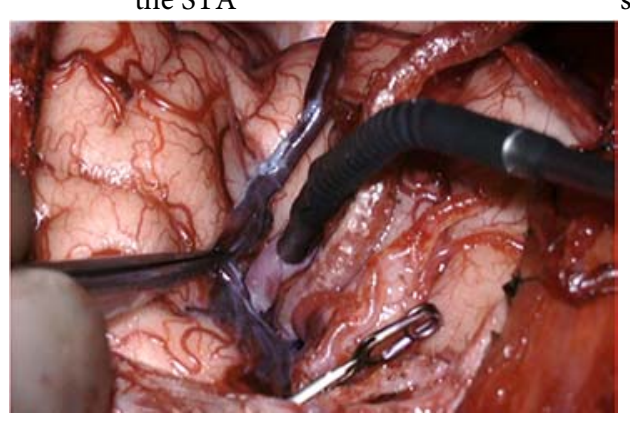

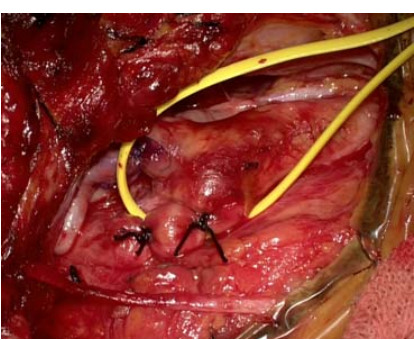

ICA permanently occluded by double ligation with a 1.0 silk

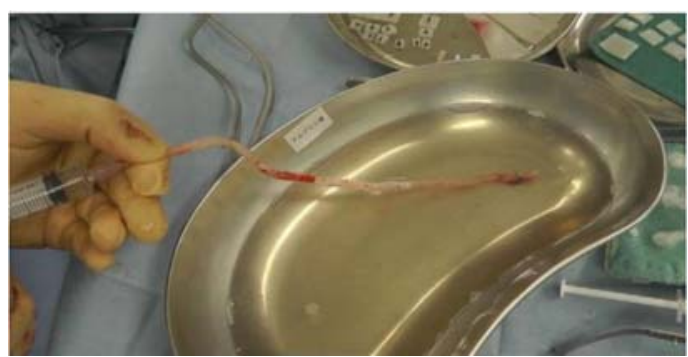

pressure distension technique is performed to prevent vasospasm

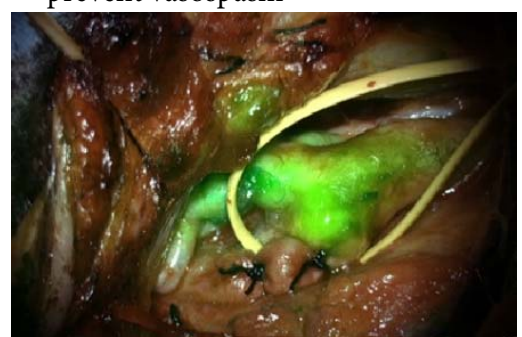

ICG and DIVA demonstrates that there is not blood flow into ICA after occlusion of ICA (previous stage)

Dopler sonography of MCA (a) and RA graft (b) after anastomosis.

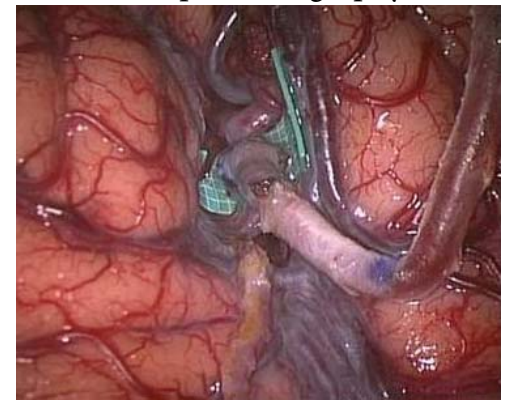

Final image of RA graft bypass. (Proximal view) suture
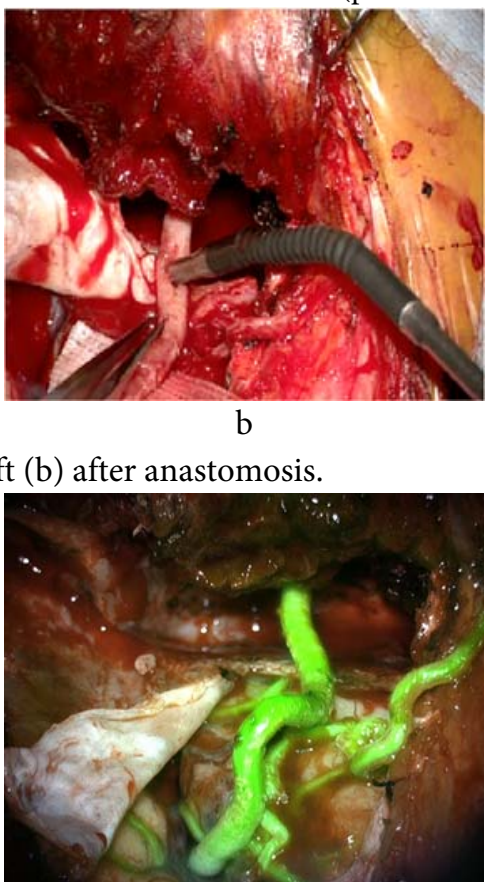

ICG and DIVA illustration of blood flow restoration after anastamosis 
Patient was treated with radial artery (RA) graft technique and ICA occlusion. Postoperative 3D-CTA and confirmed disappearance of the aneurysm and the RA graft patency.
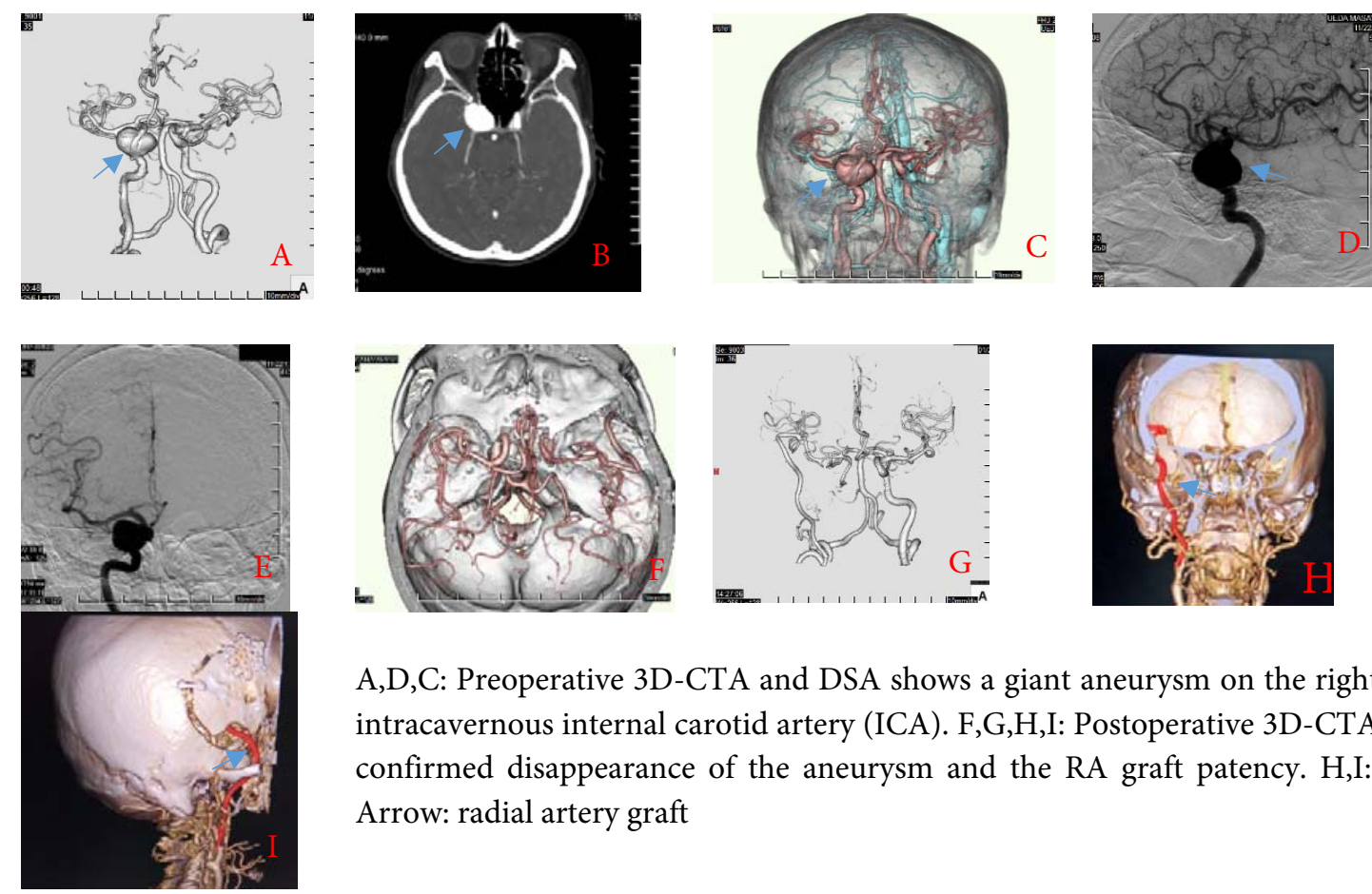

A,D,C: Preoperative 3D-CTA and DSA shows a giant aneurysm on the right intracavernous internal carotid artery (ICA). F,G,H,I: Postoperative 3D-CTA confirmed disappearance of the aneurysm and the RA graft patency. H,I:, Arrow: radial artery graft

\section{Results}

Two patients with symptomatic large and giant aneurysms of cavernous partof ICAwere evaluated as not amenable for clipping or endovascular treatment due to location and size of the aneurysm and associated high morbidity risk with these treatment options. In both cases radial artery graft was used for high-flow EC-MCA bypass and proximal internal carotid artery was ligated. Additionally, for high-flow bypass was performed superficial temporal artery (STA) to middle cerebral artery (MCA) bypass. DIVA, ICG and Doppler sonography were used multiple times to assess the patency of graft artery. In one case there was not complete ligation of the IC after postop DSA, after one month was performed reintervention to completely ligate IC. Postoperative course was uneventful, there were no mortality or morbidity. Follow-up showed good recovery and postoperative CT and DSA showed complete occlusion of ligated IC and patent functioning arterial graft. 


\section{Discussion}

Tarr et al. and Origitano et al. think that the cumulative risks of not performing revascularization in patients who tolerate ICA balloon occlusion (risk of BTO itself 3.7-7\% false negative rate of BTO 7-22\%) exceed the surgical risk of revascularization (3-7\%).

Murai et al. reported in 17 bypass surgeries cranial nerve dysfunction (III and VI) caused by altered blood flow from the ICA after occlusion was the most common complication (three cases in CCA) and typically was temporary.

Houkin et al.[4] reported in 36 patients with giant or largeaneurysms located at the cavernous portion of the ICA postoperative angiography showed patencyof bypass graft in $97 \%$ of cases. Aneurysms disappeared and thrombosed on postoperative angiography and magnetic resonance imaging, respectively.

Houkin et al and Kamiyama reported that most of the aneurysms would spontaneously thrombose after proximal ligation without the distal outflow occlusion. [4,5]

In addition, endovascular techniques have been developed to treat CCA, which included intra-aneurysmal coil embolization with or without stent or balloon-assist, and flowdiverting stent. performed intra-aneurysmal coil embolization in seven patients with large or giant symptomatic CCA. After the operation, one patient improved the symptoms of aneurysmal mass effect, two patients unchanged and four patients deteriorated. They concluded that intraaneurysmal coil embolization is not an effective treatment option for large or giant CCA. [6]
According to a recent report, a flow diverting stent has been developed for the effective treatment of an unruptured giant symptomatic CCA;[7] however, early,[8] and delayed $[9,10]$ rupture of the aneurysm after treatment has been described. The incidence delayed ruptured of an aneurysm after the stent is $0.6-1 \%$, but was not reported for early rupture. The risk factor is aneurysm size 10 mm or larger.[9]

In cases of a ruptured aneurysm with flow divertingstent treatment, the blood flow entered the aneurysm saccontinuously without intra-aneurysmal pressure reductionimmediately after device deployment. Furthermore, it wasnecessary to use the antiplatelet agent during the perioperativeperiod after stenting. Therefore, prompt prevention of theaneurysmal rerupture could not be obtained.[11]

Hasegawa et al reported In cases with direct CCF (carotid cavernous fistula) due to ruptured however, endovascular management was not always available on an urgent basis in some institutes and was not always successful, in which case direct surgical trapping of the lesion and distal bypass might be indicated. [12]

Little et al.[13] reported 15 cases of symptomatic CCA weretreated with different methods of ICA occlusion withouthigh-flow bypass. Good results were achieved in most cases,but delayed ipsilateral cerebral ischemia was found in twocases (13\%), and partial retrograde filling of the aneurysmwas demonstrated in three cases.

Postoperative complications of six case series are summarized in Table 2 . $[13,4,14,15,17,16]$ 
Table 2 - List of complications

\begin{tabular}{|c|c|c|c|c|c|}
\hline Ischemic stroke & $\begin{array}{l}\text { Cranial nerve } \\
\text { palsy }\end{array}$ & $\begin{array}{l}\text { Ruptured } \\
\text { Acom } \\
\text { aneurysm }\end{array}$ & $\begin{array}{l}\text { De novo } \\
\text { aneurysm } \\
\text { formation }\end{array}$ & $\begin{array}{l}\text { Delayed re- } \\
\text { enlargement } \\
\text { of CCA }\end{array}$ & $\begin{array}{l}\text { Epilepsy due to } \\
\text { hyperperfusion } \\
\text { syndrome }\end{array}$ \\
\hline $\begin{array}{l}2 / 15 \text { cases }(13 \%) \\
\text { One case for STA-MCA bypass } \\
\text { with Selverstone clamp } \\
\text { occlusion } \\
\text { One for ICA ligation) } \\
{ }^{\star} \text { Mean follow-up period } 5.6 \\
\text { years }\end{array}$ & $\begin{array}{l}\mathrm{CN} 3, \mathrm{CN} 5 \text { palsy } \\
2 / 15 \text { cases }\end{array}$ & No & No & No & No \\
\hline $\begin{array}{l}\text { 1/36 cases }(2.8 \%) \\
\text { RA graft occlusion } \\
{ }^{\star} \text { Mean follow-up period } 7.2 \\
\text { years }\end{array}$ & No & No & No & No & No \\
\hline $\begin{array}{l}3 / 11 \text { cases }(27.3 \%) \\
\text { Early } 1 \text { case } \\
\text { Delayed } 2 \text { cases } \\
{ }^{*} \text { Mean follow-up period } \\
13.9 \text { years }\end{array}$ & No & \begin{tabular}{|l} 
Ruptured \\
Acom \\
aneurysm \\
$(1$ case $)$
\end{tabular} & $\begin{array}{l}(2 \text { cases, } \\
\text { contralateral } \\
\text { CCA } \\
\text { and Acom })\end{array}$ & $\begin{array}{l}\text { Delayed re- } \\
\text { enlargement } \\
\text { of CCA ( } 2 \\
\text { cases) }\end{array}$ & No \\
\hline $\begin{array}{l}0 \% \\
{ }^{\star} \text { Mean follow up period } \\
5.2 \text { years }\end{array}$ & $\begin{array}{l}\text { CN3,6 palsy (3/13 } \\
\text { cases) }\end{array}$ & No & No & No & No \\
\hline $\begin{array}{l}2 / 12 \text { cases }(16.7 \%) \\
\text { Both are embolic stroke } \\
\text { One case is asymptomatic }\end{array}$ & \begin{tabular}{|l|}
$\mathrm{CN} 2$ ( 1 case $)$ \\
$\mathrm{CN} 3,4$ ( 2 cases $)$ \\
$\mathrm{CN} 3,4,6$ ( 1 case $)$ \\
$\mathrm{CN} 6$ ( 1 case $)$ \\
\end{tabular} & No & No & No & No \\
\hline $\begin{array}{l}1 / 8 \text { cases }(12.5 \%) \\
\text { A small ipsilateral frontal } \\
\text { ischemia (transient dysarthria } \\
\text { and gait disturbance) } \\
{ }^{\star} \text { Mean follow-up period } \\
3.15 \text { years }\end{array}$ & CN4 (1 case) & No & No & No & $\begin{array}{l}\text { Epilepsy due to } \\
\text { hyperperfusion } \\
\text { syndrome ( } 1 \text { case) }\end{array}$ \\
\hline
\end{tabular}

\section{Conclusions}

Cavernous carotid aneurysms (CCA) are rare and pose considerable challenges in management. A bypass procedure before parent artery occlusion, preferable to reduce the risks of postocclusion stroke.

For CCA with mass effect, high-flow bypass with proximal occlusion of ICA (without trapping) seems to be the first choice treatment for large and giant CCA because of the high rate of aneurysm thrombosis.

In our case series, the RA proved to be a useful graft for cerebral revascularization. Its long-term patency has been demonstrated in the surgical management of giant aneurysms of the cavernous and paraclinoid ICAs. The 
RA has a lumen that closely approximates that of the M2 segment, and it has the advantage of being a physiological conduit for arterial blood. Unlike venous grafts, the RA lacks valves and varices, and is technically easier to harvest because of its consistent anatomical location and size. More resistant to kinking than the SV, the RA is preferable to this vein, whose flow mismatch can lead to subsequent flow turbulence and graft thrombosis. The RA grafts can better tolerate intermittent temporary occlusion when compared with vein grafts, whose valves and endothelium can promote thrombosis in lowflow states $[18,19]$.

Intraoperative Doppler sonography and DIVA makes it easy to check the patency of the graft. DIVA is superior over Doppler or ICG in terms of better visualization of related anatomical structures.

\section{References}

1. Sheau Fung Sia, Michael Kerin Morgan. High flow extracranial-to-intracranial brain bypass surgery. Journal of Clinical Neuroscience. Volume 20, Issue 1, January 2013, Pages 1-5

2. Russell SM, Jafar JJ. Microsurgical treatment of intracavernous carotid artery aneurysms. In: Le Roux PD, Winn RH, Newell DW, editors. Management of Cerebral Aneurysms. Philadelphia: Saunders; 2004. p. 711-29.

3. Linskey ME, Sekhar LN, Hirsch WL Jr., Yonas H, Horton JA. Aneurysms of the intracavernous carotid artery: Natural history and indications for treatment. Neurosurgery 1990;26:933-7.

4. Houkin K, Kamiyama H, Kuroda S, Ishikawa T, Takahashi A, Abe H.Long-term patency of radial artery graft bypass for reconstruction ofthe internal carotid artery. Technical note. J Neurosurg 1999;90:786-90.

5. Kamiyama H. Bypass with radial artery graft. No Shinkei Geka1994;22:911-24.
6. Morita K, Sorimachi T, Ito Y, Nishino K, Jimbo Y, Kumagai $\mathrm{T}$, et al. Intra-aneurysmal coil embolization for large or giant carotid artery aneurysms in the cavernous sinus. Neurol Med Chir (Tokyo) 2011;51:762-6.

7. Szikora I, Berentei Z, Kulcsar Z, Marosfoi M, Vajda $\mathrm{ZS}$, Lee $\mathrm{W}$, et al. Treatment of intracranial aneurysms by functional reconstruction of the parent artery: The Budapest experience with the pipeline embolization device. AJNR Am J Neuroradiol 2010;31:1139-47.

8. Turowski B, Macht S, Kulcsár Z, Hänggi D, Stummer W. Early fatal hemorrhage after endovascular cerebral aneurysm treatment with a flow diverter (SILK-Stent): Do we need to rethink our concepts? Neuroradiology 2011;53:37-41.

9. Lin LM, Colby GP, Jiang B, Pero G, Boccardi E, Coon AL. Transvenous approach for the treatment of direct carotid cavernous fistula following pipeline embolization of cavernous carotid aneurysm: A report of two cases and review of the literature. BMJ Case Rep 2014;2014. pii: Bcr2014011235.

10. Kallmes D, Boccardi E, Bonafe A, Cekirge S, Fiorella D, Hanel R, et al. O-009 Safety of flow diversion: Results from a multicenter registry. J Neurointerv Surg 2013;5 Suppl 2:A6. [Abstr].

11. Schneiders JJ, VanBavel E, Majoie CB, Ferns SP, van den Berg R. A flow-diverting stent is not a pressurediverting stent. AJNR Am J Neuroradiol 2013;34:E1-4.

12. Hasegawa $H$, Inoue $T$, Tamura A, Saito I. Urgent treatment of severe symptomatic direct carotid cavernous fistula caused by ruptured cavernous internal carotid artery aneurysm using high-flow bypass, proximal ligation, and direct distal clipping: Technical case report. Surg Neurol Int 2014;5:49.

13. Little JR, Rosenfeld JV, Awad IA. Internal carotid artery occlusion for cavernous segment aneurysm. Neurosurgery 1989;25:398-404.

14. Niiro M, Shimozuru T, Nakamura K, Kadota K, Kuratsu J. Long-term follow-up study of patients with cavernous sinus aneurysm treated by proximal occlusion. Neurol Med Chir (Tokyo) 2000;40:88-96.

15. Murai Y, Teramoto A, Mizunari T, Kobayashi S, Kamiyama H. Treatment of complex internal carotid artery aneurysm using radial artery grafts. Surg Cereb Stroke 2007;35:387-93.

16. Murai Y, Mizunari T, Umeoka K, Tateyama K, Kobayashi S, Teramoto A. Radial artery grafts for 
symptomatic cavernous carotid aneurysms in elderly patients. Neurol India 2011;59:537-41.

17. Shimizu H, Matsumoto Y, Tominaga T. Parent artery occlusion with bypass surgery for the treatment of internal carotid artery aneurysms: Clinical and hemodynamic results. Clin Neurol Neurosurg 2010;112:32-9.
18. Surdell DL, Hage ZA, Eddleman CS, Gupta DK, Bendok BR, Batjer HH. Revascularization for complex intracranial aneurysms. Neurosurg Focus 2008;24:E21.

19. Kocaeli H, Andaluz N, Choutka O, Zuccarello M. Use of radial artery grafts in extracranial-intracranial revascularization procedures. Neurosurg Focus 2008;24:E5. 